\title{
ACADEMIA
}

Accelerating the world's research.

\section{Not all rejections are alike; competence and warmth as a fundamental distinction in social rejection}

Marrie Bekker, Joris Lammers

Journal of Experimental Social Psychology

\section{Cite this paper}

Downloaded from Academia.edu $₫$

Get the citation in MLA, APA, or Chicago styles

\section{Related papers}

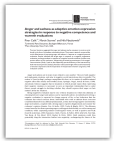

Anger and sadness as adapt ive emotion expression strat egies in response to negat ive comp... Nils Myszkowski

Affective transitions in negotiation

Sigal Barsade

Emotion is for influence

Lukas Koning 


\title{
Not all rejections are alike; competence and warmth as a fundamental distinction in social rejection
}

\author{
Pinar Çelik ${ }^{\mathrm{a}, *}$, Joris Lammers ${ }^{\mathrm{b}}$, Ilja van Beest ${ }^{\mathrm{b}}$, Marrie H.J. Bekker ${ }^{\mathrm{c}}$, Roos Vonk ${ }^{\mathrm{d}}$ \\ a Department of Social Psychology, Faculty of Social and Behavioral Sciences, Tilburg University, Warandelaan 2, 5037 AB Tilburg, The Netherlands \\ ${ }^{b}$ Department of Social Psychology, Tilburg University, The Netherlands \\ c Department of Clinical Psychology, Tilburg University, The Netherlands \\ d Department of Social and Cultural Psychology, Montessorilaan 3, 6525 HR, Nijmegen, The Netherlands
}

\section{H I G H L I G H T S}

- Adaptive emotional reactions to social rejection

- Compare effects of rejection due to lack of competence and due to lack of warmth

- Rejection due to lack of competence primarily leads to anger

- Rejection due to lack of warmth primarily leads to sadness

\section{A R T I C L E I N F O}

\section{Article history:}

Received 15 March 2012

Revised 19 February 2013

Available online 26 February 2013

\section{Keywords:}

Social rejection

Competence warmth

Social perception

Emotion

\begin{abstract}
A B S T R A C T
Social rejection can lead to a variety of emotions. Two studies show that specific emotional reactions to social rejection can be understood by relying on the fundamental distinction between competence and warmth. Rejection that is perceived to be due to incompetence leads to anger, whereas rejection that is perceived to be due to lack of warmth leads to sadness. Study 1 measures perceptions of competence and warmth judgments. Study 2 manipulates those perceptions. In both studies, rejection that was perceived to be the result of incompetence led primarily to anger, while rejection that was perceived to be the result of lack of warmth led primarily to sadness. These results show that the effects of rejection can be better understood if we take into account how rejection is perceived.
\end{abstract}

(c) 2013 Elsevier Inc. All rights reserved.

\section{Introduction}

In the past two decades the phenomenon of social rejection has received a lot of attention (Baumeister, Brewer, Tice, \& Twenge, 2007; Gerber \& Wheeler, 2009; Williams, 2001, 2007). Among the most contradictory reactions to rejection are the emotions that people experience when they are rejected. Rejection can elicit sadness, but it can also lead to anger (Chow, Tiedens, \& Govan, 2008; Leary, Twenge, \& Quinlivan, 2006; Richman \& Leary, 2009; Van Beest \& Williams, 2006; Van Beest, Williams, \& van Dijk, 2011; see Gerber \& Wheeler, 2009 for an overview). The fact that rejection leads to both anger and sadness does not appear puzzling at first sight. After all, both are negative, unpleasant emotions. However, looking at these emotions from a functional perspective, it is clear that they are very different from each other, each with different antecedents and behavioral consequences (Ekman, 1992; Frijda, 1987; Frijda, Kuipers, \& Ter Schure,

\footnotetext{
* Corresponding author.

E-mail addresses: P.Celik@uvt.nl (P. Celik), J.Lammers@uvt.nl (J. Lammers), I.vanBeest@uvt.nl (I. van Beest), M.H.J.Bekker@uvt.nl (M.H.J. Bekker), Vonk@psych.ru.nl (R. Vonk).
}

1989; Keltner \& Gross, 1999; Van Kleef, De Dreu, \& Manstead, 2010; Zeelenberg, Nelissen, Breugelmans, \& Pieters, 2008).

Specifically, sadness is an emotion that is typically part of a "horizontal" managing of interpersonal relationships. Showing sadness elicits nurturance from others (Vingerhoets, Cornelius, Van Heck, \& Becht, 2000; Zeifman, 2001). Within the individual it leads to feelings of helplessness that can help to motivate the individual to actively reach out to others (Gray, Ishii, \& Ambady, 2011; Shaver, Schwartz, Kirson, \& O'Connor, 1987). In contrast, anger is part of a "vertical" managing of interpersonal relationship. It signals dominance and toughness, causing others to concede more quickly (Knutson, 1996; Sinaceur \& Tiedens, 2004; Van Beest, Van Kleef, \& Van Dijk, 2008). Anger is an energizing emotion that motivates the individual to reassert power and status through competition, or frightening others into compliance (Kassinove, Roth, Owens, \& Fuller, 2002; Keltner \& Haidt, 1999; Lelieveld, Van Dijk, Van Beest, \& Van Kleef, 2012; Shaver et al., 1987; Van Kleef, 2010). In line with this idea, Tiedens, Ellsworth, and Mesquita (2000) showed that people expressing anger were perceived as being of higher status than people expressing sadness. Thus, in many ways anger and sadness are opposites, or even orthogonal to each other. How can rejection have such opposite effects on emotions? We propose that if we define rejection 
beyond the mere fact of being left out and specify the rejection experience we can account for this seeming contradiction and obtain a clearer image of the consequences of rejection.

Our basic idea builds on the observation that social rejection is not a capricious behavior that is the result of peoples' impulsiveness; people have a reason for why they reject others. When we take a closer look at the main manipulation techniques used to induce feelings of rejection, cyberball (Williams \& Jarvis, 2006), the life alone prognosis paradigm (Baumeister, Twenge, \& Nuss, 2002) or the get acquainted paradigm (Nezlek, Kowalski, Leary, Blevins, \& Holgate, 1997), they all have in common that subjects do not get much information regarding the possible reason of rejection. Subjects suddenly no longer get the ball passed (in the cyberball paradigm), or are told that they will lead a lonely life without friends (in the life alone paradigm). Subjects are either rejected or not, but they are never told why. Although this of course has the benefit of testing the "pure" effect of rejection without any additional information, these manipulations ignore the complexity of the experience of rejection. After all, in practice people are almost never rejected out of the blue. People accept and reject others based on specific perceptions and judgments of them (Kurzban \& Leary, 2001). Moreover, when people are the victim of rejection themselves-especially when there is no apparent reasonthey will also think about the possible judgments and perceptions that their rejecters have about them (Wirth \& Williams, 2009).

Rejection is thus a highly social phenomenon where interpersonal perceptions and meta-perceptions on why this rejection occurred play a key role. In the current paper we aim to demonstrate that people's perceptions of the reasons why they are rejected critically shape their emotional reactions. We expect that if people are rejected, they are highly motivated to find out why. This idea is supported by the fact that when people are ignored for no apparent reason, they either assume inadequacies in ones' self, attribute intent to the rejecter, or look for mitigating circumstances (Geller, Goodstein, Silver, \& Sternberg, 1974). Social rejection often leads to a drop in self-esteem, suggesting that people worry about how they look in the eyes of their rejecter and others (Leary, Cottrell, \& Phillips, 2001; Van Beest \& Williams, 2011; Zadro, Williams, \& Richardson, 2004).

We propose here that perceptions about the reasons of social rejection can be best understood by relying on the distinction between interpersonal warmth and competence. In the social perception literature, warmth and competence are seen as core and universal components of interpersonal perception (Cuddy, Fiske, \& Glick, 2008; Fiske, Cuddy, \& Glick, 2007). When people evaluate individuals on competence they rely on characteristics such as skill, creativity, intelligence, foresight and competitiveness, whereas when they evaluate individuals on warmth they rely on characteristics such as friendliness, sincerity, helpfulness, trustworthiness and cooperativeness. The distinction between these two domains goes back many decennia, and was first described referring to the orthogonal axes of circumplex models (Leary, 1957). The vertical axe reflects hierarchical relations involving rank and status whereas the horizontal axe reflects communal relations involving love and affiliation (Kiesler, 1983; Wiggins, 1979; Wiggins \& Broughton, 1985). These axes since then have been variously labeled as power vs. love, agency vs. communion or dominance vs. affiliation. Despite the different labels, research suggests a substantial overlap between these conceptual opposites (Abele \& Wojciszke, 2007). The dominant labeling in contemporary research is competence vs. warmth. Recent studies have shown that people everywhere differentiate each other by liking (warmth, trusting) and respecting (competence, efficiency). Moreover, $82 \%$ of the variance in everyday perceptions of others can be accounted for by judgments pertaining to competence and warmth (Wojciszke, 2005; Wojciszke, Bazinska, \& Jaworski, 1998).

In the current paper, we aim to demonstrate that perceptions of warmth and competence judgments lie at the core of the rejection experience by showing very specific and meaningful effects of social rejection on emotions. We base our reasoning on the notion that the functional aspects of emotions typically observed after social rejection-anger and sadness-converge with the vertical and horizontal aspects of relationships that underlie the warmth-competence model. Based on the notion that individuals will always seek to understand their social environment (Kelley, 1973) and will think about ways to undo or repair what has been damaged by the rejection, we expect that rejection that is (perceived to be) due to lack of warmth should lead to distinct emotional reactions compared to rejection that is (perceived to be) due to lack of competence.

\section{Predictions}

Specifically, we propose that, if rejected participants perceive that those who rejected them believe they lack warmth, they should primarily experience sadness, while if they perceive that their rejection is due to their lack of competence, they should primarily experience anger. This reasoning follows from a social-functional account of emotions as means of coordinating social interactions and relationships to meet specific problems (e.g., Averill, 1992; Tooby \& Cosmides, 1990).

A rejection based on lack of warmth is basically a message that one is not liked. This is associated with the appraisal that one cannot do much about this judgment; whether one is liked or not is outside one's control and may even induce a sense of helplessness. The consequence is that the individual will seek the specific type of social resource that will reduce this sense of helplessness. We argue that sadness is an appropriate response because it evokes sympathy from others. Sadness signals to the outside world that one is a warm person and in turn elicits the kind of social support that was damaged by this type of rejection (Vingerhoets et al., 2000; Zeifman, 2001). Participants should not experience much anger, because anger does not signal warmth. In fact, prior research has shown that it may even undermine social support (Lelieveld et al., 2012; Wubben, De Cremer, \& Van Dijk, 2009). Importantly, we do not contend that anger will be totally absent, but this emotion will mainly emerge because rejections are very often perceived as unfair (Lind \& Tyler, 1988).

Conversely, we propose that if participants perceive that their rejection is caused by the fact that those who rejected them believe they lack competence, they should primarily experience anger. A lack of competence means that others are better and higher in rank, which should elicit the desire to compete. We know from previous research that anger is specifically functional in restoring competence and status - anger not only motivates and orients the individual towards action, but also causes others to concede more quickly (Kassinove et al., 2002; Tiedens, 2001; Van Kleef, 2010). Participants should experience less sadness, because sadness is associated with passivity and inhibition (Shaver et al., 1987) and is therefore a poor aid in restoring competence and status (Tiedens, 2001). Again, we do not contend that sadness will be totally absent in reaction to a (perceived) competence rejection, but this emotion will be mainly directed at individuals who are perceived as supportive in regaining competence, e.g. good friends or family. People will not show sadness towards the ones who are perceived as the 'competition'.

In sum, we propose that social rejection should lead to two fundamentally opposite emotional reactions, depending on whether that rejection is perceived to be due to lack of warmth or lack of competence.

\section{Overview of studies}

We test these predictions in two studies. In Study 1 we measure the perception of rejection. That is, in this study, an ostensible other participant (a confederate), for unclear reasons, socially rejects the participant. The rejection is accompanied by mildly negative warmth and competence judgments, ostensibly coming from this other participant (the confederate). We then measure how the participant (the target of the rejection) perceives those judgments. We expect that these perceptions will differentially predict feelings of sadness 
and anger in the participant. In Study 2 we manipulate the perception of rejection. More specifically, the participant is again rejected by an ostensible other participant, but now unambiguously. That is, the participant is either rejected for lacking competence, for lacking warmth (in the eyes of the other participant), or is not rejected. We show that a rejection due to lack of competence causes different emotional reactions than a rejection due to lack of warmth.

\section{Study 1 - effects of unspecific rejection on emotions}

In Study 1 we measured perceptions of warmth and competence. In this study participants were rejected for ambiguous and unclear reasons (or were accepted), by an ostensible other participant (a confederate). Participants read simple numerical evaluations of 5 competence and 5 warmth traits presented in random order. Importantly, we did not tell our participants explicitly that they were judged on these traits, nor that these traits were related to competence and warmth. Our main assumption was that participants would use this information to make sense of the rejection and that this sense-making would be evident from how they remembered the evaluation in hind sight. We used the degree to which warmth and competence ratings were remembered as lower than actual as an indicator of how strongly the participant believed that he or she was rejected because of lack of warmth and/or competence (for a similar procedure, see Gotlib, 1983). We expected that the more participants perceived they were rejected because of lack of competence (i.e. the more they remembered the competence ratings to be lower than they were in reality) the angrier they would be, whereas the more they perceived they were rejected because of lack of warmth (i.e. the more they remembered the warmth ratings to be lower than they were in reality), the sadder they would be.

\section{Method}

\section{Participants and design}

In return for course credit, 60 first year psychology students of Tilburg University $\left(M_{\mathrm{age}}=19.7\right.$ years; 57 women) were randomly assigned to one of two experimental conditions (social rejection vs. acceptance).

\section{Procedure}

Participants were briefly introduced to a female confederate and were told that they would participate in a study about first impressions. During this brief meeting the confederate made some short neutral remarks. To set the stage for the rejection manipulation, participants were told that they would meet their partner (the confederate) again in a second, unrelated study, but that both would first indicate their impressions of each other (as part of the first study). The participant and confederate were then seated in individual adjacent cubicles within hearing range, where both the participant and confederate were instructed to rate their partner on ten traits. Five of these traits were related to warmth (likeable, sympathetic, trustworthy, nice, and kind) and five to competence (wise, sensible, has a valuable opinion, can be taken seriously, has something useful to say) (Cuddy et al., 2008). Participants were asked how much they thought each trait fitted their partner on a scale between 1 and 10, with the option to give half marks (e.g. 51/2). We chose this 10 point scale because it corresponds to the standard Dutch educational grading system (where everything below 6 is a fail grade) and thus ensured strong evaluative associations. After about $5 \mathrm{~min}$, the experimenter collected participants' rating form and handed them the ratings that the confederate had supposedly completed at the same time about them. In reality all participants received the same ratings that were prepared in advance. Thus all participants received the same grades independent of experimental condition. These ratings ranged between 4.5 and 8 . In the Dutch system, an 8 equals a score that is very good, while a 4.5 equals a score that would be a clear fail-grade. On both the warmth and competence domains, the mean rating was 7 (which equals a B or B + in the US). On both domains there were low (4.5) and high (8) ratings, to ensure that a rejection on either trait would be seen as realistic and believable. Note that these traits were presented in randomized order and were not explicitly labeled with competence and warmth to ensure the ambiguous nature of the evaluation.

Rejection manipulation. Next, participants in the rejection condition heard the confederate (in the adjacent cubicle) loudly express to the experimenter her unwillingness to continue with the second study, pack her belongings and leave. The experimenter then explained to the participant that their 'partner' (the confederate) had left without giving further explanation, but that she did fill out the rating form, and asked the participant whether (s)he still wanted to continue with the study. All participants indicated that they wanted to continue. Participants in the control condition did not hear anything of the above, so they remained under the assumption that they would still meet their partner. The experimenter then handed the rating form (supposedly filled in by the other participant who had left) to the participant and left the cubicle saying she would get the next set of questionnaires so that participants could view the ratings in private. After about $20 \mathrm{~s}$ the experimenter returned to the participant with a booklet containing the main dependent measures. Before leaving the cubicle she collected all other materials, including the rating form.

\section{Measures}

First, we measured our main dependent variables, sadness and anger, by asking participants to rate their (dis)agreement with two statements: 'I feel sad' and 'I feel angry' on two 7-point scales ranging from totally disagree (1) to fully agree (7).

Next, we measured how participants perceived the rejection experience by asking them to remember as best as possible the trait ratings they received from their 'partner' (i.e. the traits related to competence and warmth). Under the guise of a study on memory, all participants were asked to recall and write down the 10 ratings that the confederate had previously given them, on an empty rating form that included the same traits as shown before (likeable, sensible, etc.). Note that the form containing the ratings was previously collected by the experimenter. Hence, participants had to guess. For our main analyses we computed difference scores separately for the warmth and competence items by subtracting the actual ratings from the recalled ratings, which resulted in 5 difference scores for each domain. These difference scores were then summed into two composite variables - recall of warmth ratings and recall of competence ratings - with 0 -scores indicating correct recall, negative scores indicating a lower than actual rating, and positive scores indicating a higher than actual rating.

Next, as a manipulation check, we asked all participants in the rejection condition whether they had heard the confederate express the unwillingness to continue cooperating in the next part of the study. All participants indicated that they in fact had. Finally, participants were thanked and debriefed.

Results

\section{Preliminary analyses}

To make sure that our results were not due to differences in partner evaluations, we first checked whether participants differed in how they rated their partners depending on condition. Note that these ratings were collected before the rejection experience and hence we expected no difference between conditions. This was indeed the case, there was no difference between conditions in how participants rated their partner on warmth and competence, $t(58)=-.84$, ns. Overall, participants had a favorable opinion about their partner, with a mean rating of 7.6 on a scale from 1 to $10(S D=0.57)$. 


\section{Main analyses}

To test our main predictions, we ran two regression analyses. Specifically, we expected that, compared to respondents in the control condition, sadness scores would be exclusively predicted by meta-perceptions of lack of warmth (i.e. a more negative recall of warmth item ratings), whereas anger scores would be exclusively predicted by meta-perceptions of lack of competence (i.e. a more negative recall of competence item ratings). In both regression analyses we entered as predictors Condition $(1=$ rejection; $0=$ acceptance), Warmth-perception (composite mean of recalled warmth ratings minus actual warmth ratings), Competence-perception (composite mean of recalled competence ratings minus actual competence ratings) and their interactions with condition.

Sadness is predicted by perceptions of lack of warmth. As expected, sadness scores were only predicted by the condition $\times$ warmth interaction, $B=-.38, p=.06$. The condition $\times$ competence-perception interaction was not significant $(B=.20, p=.31)$, and neither were there any main effects of condition $(B=-.003, \quad p=.99)$, warmth-perception $(B=-.16, p=.43)$ or competence-perception $(B=-.24, p=.22)$. Simple slope analyses showed that in the rejection condition warmth-perception was negatively related to feelings of sadness $B=-.54, p=.04$; the lower the recall scores of the warmth items were, the higher the sadness scores were in the rejection condition. In the control condition there was no relationship between warmth-perception and sadness, $B=.23, p=.45$. This means that after rejection sadness is only predicted by perceptions of lack of warmth, but not by perceptions of lack of competence. See Fig. 1, left pane.

Anger is predicted by perceptions of lack of competence. The same analysis, this time with anger scores as the dependent variable, revealed that anger scores were only predicted by a significant rejection $\times$ competence-perception interaction, $B=-.54, p=.03$. The condition $\times$ warmth interaction was not significant $(B=-.20$, $p=.41)$. Again, we found no main effects of condition $(B=-.10$, $p=.66)$, warmth-perception $(B=-.05, p=.83$ ) or competenceperception $(B=-.09, p=.71)$. Simple slope analyses now showed that in the rejection condition competence-perception was negatively related to feelings of anger, $B=-.62, p=.05$; the lower the recall scores of the competence items were, the higher the anger scores were in the rejection condition. In the control condition there was no relationship between competence-perception and anger, $B=.45$, $p=.21$. This means that after rejection anger is only predicted by perceptions of lack of competence, but not by perceptions of lack of warmth. See Fig. 1, right pane.

\section{Post hoc analyses}

We also checked whether memory was affected by condition. A $2 \times 2$ (Condition [between: rejection, acceptance] $\times$ Recall [within: competence, warmth]) repeated measures ANOVA revealed no main effect of condition $F(1,58)=1.60$, nor a condition $\times$ recall effect, $F(1,58)=1.09$. This means that rejection did not affect memory; between conditions participants were fairly equal in how they remembered the warmth and competence ratings. We did find a non-interesting main effect of recall, $F(1,58)=18.86, p<.001$, showing that participants underestimated competence ratings $(M=-1.54, S D=2.03)$ more than warmth ratings $(M=-0.29, S D=1.66)$. This makes sense given that our participants were students and therefore perhaps more pre-occupied with competence than with warmth.

\section{Discussion}

The results of Study 1 show that exposing participants to an ambiguous rejection experience is related to different emotional reactions, depending on why participants thought they were rejected; the part of the rejection that participants attributed to lack of warmth, uniquely predicted sadness, whereas the part of the rejection that participants attributed to lack of competence uniquely predicted anger. These results could not be explained by memory, as participants who were rejected did not make more or less mistakes in remembering the ratings they received. Yet these results rely on observing individual differences in perceptions of competence and warmth judgments. To gather more direct, causal evidence, Study 2 therefore manipulates the type of rejection.

\section{Study 2 - effects of specific rejection on emotions and behavior}

In Study 2, participants were exposed to a warmth or competence rejection manipulation or to a no rejection condition. They read an unambiguous clear reason of why they were rejected. The experimental set up was similar to our previous study, however this time participants received negative evaluations either on all of the warmth traits, or on all of the competence traits, while in the acceptance condition participants received positive evaluations on all traits. We expected that a rejection due to lack of competence would lead to anger (and less to sadness); while a rejection due to lack of warmth would lead to sadness (and less to anger). Furthermore, in Study 2 we sought to increase the reliability of our measurement of anger and sadness by including additional externalizing (anger-related) and internalizing (sadness-related) emotion items.

Note that we did not hypothesize on differences between the two types of rejection, e.g. whether a rejection due to lack of warmth would lead to more sadness and less anger than a rejection due to competence. Our main point is that within the two types of rejection, one type of emotion will be more prominent than the other one.

\section{Sadness}

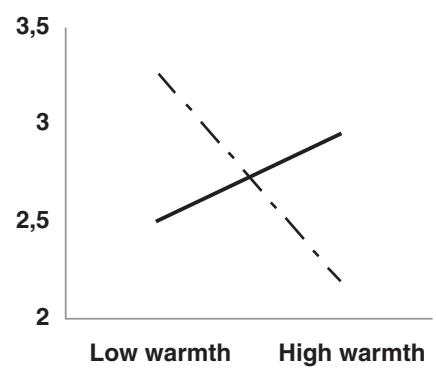

Anger

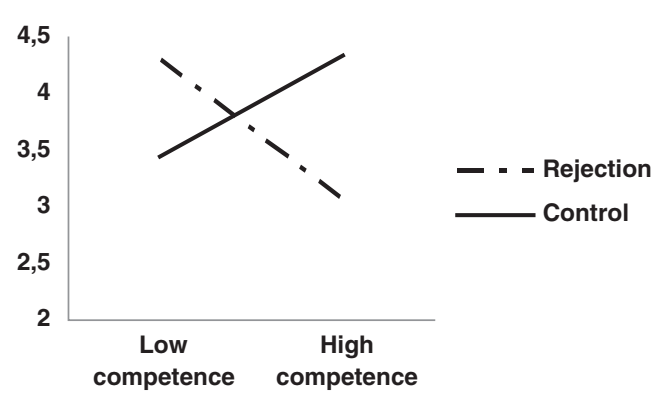

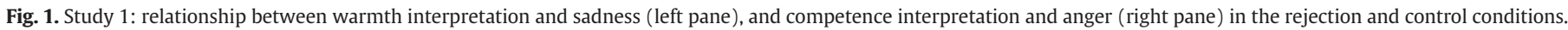




\section{Method}

\section{Participants and design}

In return for course credit, 67 first year psychology students of Tilburg university ( 55 women; $M_{\text {age }}=19.3$ years) were randomly assigned to one of three experimental conditions (competence rejection, warmth rejection, acceptance).

\section{Procedure}

Participants were told that they were participating in a study on indirect impression formation that investigated the ways in which impressions were formed in the absence of face-to-face interaction. They were told that their (ostensible) partner (in this study there was no confederate physically present) was already working in a different cubicle. It was explained that they would exchange written information with each other, which they would use to form an impression of each other (for a similar procedure, see Mallott, Maner, DeWall, \& Schmidt, 2009). To make the rejection manipulation possible participants were told that they could meet their partner afterwards if desired.

Next, participants started working (in individual cubicles) on the forms that would ostensibly be delivered to their partner by the experimenter as part of the study on impression formation. They received a booklet containing a bogus personality test and bogus open ended questions about four hypothetical but realistic social situations. We included these items to boost realism of the experiment (i.e. that participants could form an actual opinion of each other, on the basis of which they could either reject or not). Participants believed that their partner was already filling out the same booklet. After about $10 \mathrm{~min}$ (during which participants had ample time to complete the booklet) the experimenter collected the booklet, supposedly brought it to the partner and came back delivering the booklet that was supposedly filled out by their partner, together with an empty rating form. The rating form contained the same ten warmth and competence items used in Study 1. The experimenter instructed participants to carefully read the information their partner had provided them and then indicate their impression of their partner using the rating form. Similar to procedures in Study 1, all items on the form were randomized and completed on a scale between 1 and 10.

Rejection manipulation. Next, participants were asked to indicate whether they wanted to meet their partner, with a 'yes-no' checkbox. In addition, participants were given the option to write a short personal message to explain their choice, if desired. After about $5 \mathrm{~min}$, the experimenter picked up participants' ratings about their partner and gave them the rating form that their partner had supposedly completed about them.

In both rejection conditions, participants read that their partner did not want to meet them. In addition, in the rejection due to lack of competence condition the form contained negative ratings (scores between 4 and 5 ) on all competence traits and positive ratings (scores between 7 and 8) on all warmth traits. In the rejection due to lack of warmth condition, the ratings were in the opposite direction: the competence ratings were positive and the warmth ratings were negative. We avoided extremely low and extremely high ratings to bolster credibility. In addition to this, in the rejection due to lack of competence (warmth) condition, their partner had supposedly written in the optional space for personal messages "You seem a very warm and likeable (intelligent and competent) person to me! But on the other hand, you don't come across as very clever (friendly), sorry!" In the control condition, the checkbox indicated that the partner wanted to meet the participant. Also, the form contained positive ratings (between 7 and 8 ) on both the competence and warmth traits. Attached was a personal message, supposedly written by the participant's partner that said "You seem a very intelligent and likeable person to me. I would like to meet you!"
Initially, we also had two additional inclusion conditions in which participants were informed about being warm, but not competent and vice versa. Results showed that these conditions were not experienced as full inclusion by our participants, as reflected by highly negative emotional responses. We therefore focused only on the three reported conditions, in which the two rejection conditions were compared to the full inclusion condition.

\section{Measures}

After participants read how their partner evaluated them and that their partner was, or was not interested in meeting them afterwards, we measured sadness (sad, gloomy, plaintive, down \& lonely; $\alpha=.93$ ) and anger (angry, irritated, insulted, annoyed \& hostile; $\alpha=.85$ ). Participants were asked to rate their (dis)agreement with each emotion on a 7-point scale ranging from totally disagree (1) to totally agree (7). Next, to check that participants had noticed the manipulation, they were asked to report their partner's choice (whether to meet or not). Finally, to be able to control for the possibility that differences in emotional reactions could be due to differences in how upset participants felt by the two types of rejection, we asked them 'how do you feel about your partners' choice?' and 'how do you feel about the evaluation you received from your partner' both on a 7-point Likert scale between very happy (1), don't care (4) and very upset ( 7$)(r=.80, p<.001)$. All participants were thanked and debriefed after finishing.

Results

\section{Preliminary analyses}

All participants successfully indicated the correct answer to the question about their partner's choice (i.e. all participants in the rejection conditions indicated that their partner did not want to meet, while all participants in the acceptance condition indicated that their partner did want to meet them). We also checked for possible differences between the rejection and acceptance conditions regarding participants' ratings of their partners. As in Study 1, these ratings were collected before the rejection experience. We found no difference between the rejection and inclusion conditions, $t(64)=-1.57$, ns. Overall, participants had a favorable opinion about their partner. Mean ratings of warmth and competence were 7.8 on a scale from 1 to $10(S D=0.59)$. Furthermore, $94 \%$ of all participants indicated that they wanted to meet their partner after the experiment. We did not exclude participants who did not want to meet their partner, as this did not affect our results.

Second, we checked whether the two rejection types were equally upsetting. An ANOVA with Condition (between: competence, warmth, acceptance) as the independent variable and the degree to which participants were upset as the dependent variable, revealed a significant main effect of condition, $F(2,64)=100.50, p<.001, \eta_{p}^{2}=.76$. Simple comparisons showed that participants felt much more upset in both rejection conditions $\left(M_{\text {competence }}=4.67, S D_{\text {competence }}=0.78 ; M_{\text {warmth }}=4.82\right.$, $\left.S D_{\text {warmth }}=0.78\right)$, compared to the acceptance condition $(M=2.04$, $S D=0.69), F(1,64)=200.26, p<.001, \eta_{\mathrm{p}}^{2}=.76$. Importantly, the two rejection conditions did not differ in the degree to which participants were upset, $F<1$.

\section{Main analyses}

Our main prediction was that we expected more sadness than anger in the rejection due to lack of warmth condition, but more anger than sadness in the rejection due to lack of competence condition. A $2 \times 2$ (Condition [between: warmth, competence, acceptance] $\mathrm{x}$ Emotions [within: sadness, anger]) repeated measures ANOVA revealed the expected condition $\times$ emotions interaction, $F(2,64)=7.636$, $p<.001, \eta_{\mathrm{p}}^{2}=.19$. As expected, simple within-group comparisons revealed that participants who were rejected because of lack of warmth reported significantly higher levels of sadness $(M=3.02, S D=1.47)$ than anger $(M=2.53, S D=1.07), F(1,21)=6.11, p=.02, \eta_{\mathrm{p}}^{2}=.23$. 


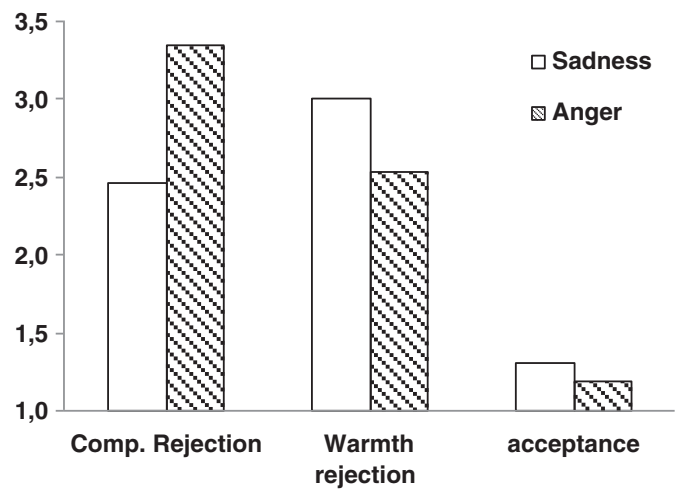

Fig. 2. Study 2: differences between levels of sadness and anger in the competence-rejection, warmth-rejection and acceptance conditions.

Conversely, participants who were rejected because of lack of competence reported higher levels of anger $(M=3.35, S D=1.16)$ than sadness $(M=2.46, S D=1.46), F(1,20)=4.86, p=.04, \eta_{\mathrm{p}}^{2}=.20$. Participants who were accepted reported equal levels of sadness $(M=1.31$, $S D=0.54)$ and anger $(M=1.19, S D=0.35), p=.23$. See Fig. 2.

Additionally, we also performed between-group comparisons. These analyses showed that anger scores were significantly higher in the rejection due to lack of competence condition compared to the rejection due to lack of warmth condition, $F(1,64)=8.70$, $p=.004, \eta_{\mathrm{p}}^{2}=.12$, and acceptance condition $F(1,64)=62.16$, $p<.001, \eta_{\mathrm{p}}^{2}=.49$. Also, sadness scores were significantly higher in the warmth rejection condition compared to the acceptance condition, $F(1,64)=22.60, p<.001, \eta_{\mathrm{p}}^{2}=.26$, but the difference with the competence rejection condition was only marginally significant, $F(1,64)=2.27, p=.14$. See Fig. 2 .

\section{Discussion}

Study 2 supported our predictions and showed that participants who experienced an explicit rejection due to lack of warmth reported higher levels of sadness than anger, whereas participants who experienced an explicit rejection due to lack of competence reported higher levels of anger than sadness. By using a very explicit form of rejection that exclusively signaled either warmth or competence as the reason for the rejection we were able to tease apart the effects of both types of rejection on emotional reactions.

\section{General discussion}

Two studies consistently show that perceptions of warmth and competence judgments in social rejection explain the emotional reactions to rejection. In Study 1 a confederate rejected (or accepted) participants for ambiguous reasons (suggesting it was due to either lack of warmth or lack of competence). Among those who were rejected, misperceptions of incompetence predicted anger, but misperceptions of coldness (lack of warmth) predicted sadness. Among those who were not rejected these effects were absent. In Study 2 we manipulated perceptions of competence and warmth judgments. Participants who were explicitly rejected because they were not warm enough were more sad than angry, while participants who were explicitly rejected because they were not competent enough were more angry then sad.

It is striking to what degree a warmth-rejection selectively increased feelings of sadness and not feelings of anger. After all, in Study 1 participants did not have any meaningful exchange with the confederate. In Study 2 participants did not even meet their supposed partner, whose behavior was scripted and purely determined by experimental condition. The rejections thus objectively lacked any legitimacy; participants were objectively not colder or warmer than any other participant. Hence, participants could have concluded that their partner's behavior was more indicative of his/her prejudice and arrogance, than of their own (lack of) warmth or competence. Objectively, the warmth-rejection showed that the confederate is a smug. It did not tell anything about the participant. Yet despite all this, respondents reacted by showing primarily sadness. Why were they not angrier? These results can be explained by going back to our theoretical model. They make sense from a functional perspective on emotions. Our findings are even more compelling considering recent research suggesting that women are ascribed higher warmth and men are ascribed higher competence (Fiske, Cuddy, Glick, \& Xu, 2002). One could hypothesize that women should be more upset by warmth rejections than competence rejections (the opposite holds for men), due to socialization processes. However, note that our sample consisted mainly of women and still we found strong reactions on competence rejections in the predicted direction. Thus despite specific gender roles that prescribe anger as a less acceptable emotion for women than for men, a competence rejection still leads to considerable levels of anger among our female participants. Our findings are in line with social-functional accounts of emotions as a means of coordinating social interactions and relationships to meet specific problems (e.g., Averill, 1992; Tooby \& Cosmides, 1990); sadness evokes sympathy in others and is ultimately directed at restoring likeability and warmth, while anger evokes fear in others and is ultimately directed at restoring respect and status (Keltner \& Gross, 1999; Keltner \& Haidt, 1999; Shaver et al., 1987; Tiedens, 2001).

Our findings demonstrate that in a rejection situation people are very sensitive to information that may indicate that they are seen as either incompetent or cold. Even when this information is presented without explicit labels (as in Study 1), it is quickly processed and seems to effortlessly lead to the discrete emotional reactions that, we assume, may be functional in that setting. In sum, responses to social exclusion seem to fit in the toolbox of automaticity that allows us to efficiently and effortlessly navigate the social world (Bargh \& Chartrand, 1999).

\section{Strengths, limitations and future directions}

We believe that our studies offer converging validity for our predictions, due to their different methodologies. The advantage of Study 1 was that participants were never explicitly asked why they thought they were rejected. They were never told that they may lack warmth or competence. In fact, the words warmth and competence were never mentioned. Participants were all given exactly the same ratings on traits such as likeable and sympathetic, and on traits such as wise and sensible. Simply by inferring their perceptions, by looking at the recalling errors that participants made, we were able to predict their emotional reactions. In comparison, Study 2 offered the advantage of experimental control. Here, we unambiguously induced either a rejection due to lack of warmth, or a rejection due to lack of competence. Both studies showed the same basic effect: the emotional effects of social rejection crucially depend on how that rejection is perceived; as due to lack of warmth, or as due to lack of competence.

A potential limitation is that we focused on emotions, we did not measure behavior. However, our main aim was to show that social rejection at the level of emotions has an initial 'corrective' effect on individuals (at least in healthy individuals); individuals who are rejected because they are (seen as) cold experience emotions directed at becoming and being seen as nicer individuals, whereas individuals who are rejected because they are (seen as) incompetent experience emotions directed at becoming and being seen as more competent. This is an important finding because it puts the idea that rejection leads to anti-social behavior in perspective (see also, Elshout, Van Beest, \& Nelissen, 2012). Additional research is needed to identify the conditions under which these initial emotional responses to rejection result in adaptive and inadaptive behaviors, such as making amends (adaptive) vs. becoming overly dependent and needy (inadaptive) in case of 
sadness, or working harder (adaptive) vs. using excessive aggression to be recognized (inadaptive) in case of anger.

One might contend that in real life rejections are often for both reasons. Future research could focus on this issue. Our first study reflects real life experiences of rejection quite well, in that both reasons for rejection were equally possible. As one would expect, we found a mixture of anger and sadness. However, with statistical modeling it became apparent that these emotions have different antecedents in terms of appraisal of the rejection. Regardless of antecedents of these emotions it is interesting to speculate about emotional and behavioral responses following this kind of rejection. Would people perhaps feel powerless as they are negatively evaluated on both dimensions and would this perhaps lead to aggression? Another interesting question is whether it would make a difference if the reason for rejection is not made explicit, and people have to rely on their gut feeling, vs. the reason is being made explicit. Finally, one could differentiate between different forms of explicit messages: the message can be verbal or written, direct or indirect.

Finally, we have exclusively focused on anger and sadness. We did so by explicitly using the items anger and sadness in Study 1. In Study 2 we expanded our anger measurement with other externalizing emotions (hostility, annoyance, irritation and insult), and our sadness measurement with other internalizing emotions (gloomy, plaintive, down and lonely). But emotions that are on a different dimension than the internalizing-externalizing dimension, for example on the approach-avoidance dimension, could be equally interesting to investigate. For example the emotion of fear elicits approach-based responses from others (Marsh, Ambady, \& Kleck, 2005) and as such would be expected to follow after a warmth rejection. This is an interesting venue for future research.

\section{Relationship to literature}

Our model describing anger and sadness as specific emotional reactions towards rejection based on lack of competence and lack of warmth could be linked to the needs threat model proposed by Williams (2007). It is conceivable that a rejection based on lack of warmth primarily threatens belongingness and/or self-esteem, whereas a rejection based on lack of competence mainly threatens control and/ or meaningful existence.

For our studies we have drawn upon knowledge from the fields of person perception and emotion research. But these fields of research could benefit from our approach as well. Our studies demonstrate that the induction of social rejection is effective in inducing meaningful processing of socially relevant information (Sacco, Wirth, Hugenberg, Chen, \& Williams, 2011); they also demonstrate the effectiveness of social rejection in eliciting specific emotions. Implementing social rejection manipulations into person perception and emotion research could thus be a fruitful way in further investigating not only the interpersonal consequences of warmth and competence judgments, but also the mechanisms behind emotions.

\section{Conclusions}

To conclude, the work reported here shows that applying social perception research and emotion research in social rejection literature offers us a better understanding of social rejection and its downstream effects. It shows that not all experiences of social rejection are alike. Understanding how people feel after a rejection requires a detailed understanding of how they interpret that rejection.

\section{References}

Abele, A. E., \& Wojciszke, B. (2007). Agency and communion from the perspective of self and others. Journal of Personality and Social Psychology, 93, 751-763. http://dx.doi.org 10.1037/0022-3514.93.5.751.
Averill, J. R. (1992). The structural bases of emotional behavior. In M. S. Clark (Ed.), Emotion. (pp. 1-24)Newbury Park, CA: Sage.

Bargh, J. A., \& Chartrand, T. L. (1999). The unbearable automaticity of being. American Psychologist, 54, 462-479. http://dx.doi.org/10.1037/0003-066X.54.7.462.

Baumeister, R. F. Brewer, L. E. Tice, D. M. \& Twenge, J. M. (2007). Thwarting the need to belong: Understanding the interpersonal and inner effects of social exclusion. Social and Personality Psychology Compass, 1(1), 506-520. http://dx.doi.org/10.1111/ j.1751-9004.2007.00020.x.

Baumeister, R. F., Twenge, J. M., \& Nuss, C. K. (2002). Effects of social exclusion on cognitive processes: Anticipated aloneness reduces intelligent thought. Journal of Personality and Social Psychology, 83, 817-827. http://dx.doi.org/10.1037/0022-3514.83.4.817.

Chow, R. M., Tiedens, L. Z., \& Govan, C. L. (2008). Excluded emotions: The role of anger in antisocial responses to ostracism. Journal of Experimental Social Psychology, 44, 896-903. http://dx.doi.org/10.1016/j.jesp.2007.09.004.

Cuddy, A. J. C., Fiske, S. T., \& Glick, P. (2008). Warmth and competence as universal dimensions of social perception: The stereotype content model and the BIAS map. Advances in Experimental Social Psychology, 40, 61-149. http://dx.doi.org/10.1016/ S0065-2601(07)00002-0.

Ekman, P. (1992). An argument for basic emotions. Cognition and Emotion, 6, 169-200. http://dx.doi.org/10.1080/02699939208411068.

Elshout, E., Van Beest, I., \& Nelissen, R. M. A. (2012). Positive behaviors of the excluded toward excluders. Poster session presented at the Annual Meeting of the Society for Personality and Social Psychology, San Diego, SD.

Fiske, S. T., Cuddy, A., \& Glick, P. (2007). Universal dimensions of social cognition: Warmth and competence. Trends in Cognitive Science, 11, 77-83. http://dx.doi.org/10.1016/ i.tics.2006.11.005.

Fiske, S. T., Cuddy, A. J., Glick, P., \& Xu, J. (2002). A model of (often mixed) stereotype content: Competence and warmth respectively follow from perceived status and competition. Journal of Personality and Social Psychology, 82, 878-902. http://dx.doi.org/ 10.1037/0022-3514.82.6.878.

Frijda, N. H. (1987). Emotions, cognitive structure and action tendency. Cognition and Emotion, 1, 115-144. http://dx.doi.org/10.1080/02699938708408043.

Friida, N. H., Kuipers, P., \& Ter Schure, E. (1989). Relations among emotion, appraisal, and emotional action readiness. Journal of Personality and Social Psychology, 57(2), 212-228. http://dx.doi.org/10.1037/0022-3514.57.2.212.

Geller, D. M., Goodstein, L., Silver, M., \& Sternberg, W. C. (1974). On being ignored: The effects of violation of implicit rules of social interaction. Sociometry, 37, 541-556. http://dx.doi.org/10.2307/2786426.

Gerber, J., \& Wheeler, L. (2009). On being rejected: A meta-analysis of experimental research on rejection. Perspectives on Psychological Science, 4, 468-488. http://dx.doi.org/ 10.1111/j.1745-6924.2009.01158.X.

Gotlib, I. H. (1983). Perception and recall of interpersonal feedback: Negative bias in depression. Cognitive Therapy and Research, 7, 399-412. http://dx.doi.org/10.1007/BF01187168.

Gray, H. M., Ishii, K., \& Ambady, N. (2011). Misery loves company: When sadness increases the desire for social connectedness. Personality and Social Psychology Bulletin, 37, 1438-1448. http://dx.doi.org/10.1177/0146167211420167.

Kassinove, H., Roth, D., Owens, S. G. \& Fuller, J. R. (2002). Effects of trait anger and anger expression style on competitive attack responses in a wartime prisoner's dilemma game. Aggressive Behavior, 28, 117-125. http://dx.doi.org/10.1002/ab.90013.

Kelley, H. H. (1973). The process of causal attribution. American Psychologist, 28, 107-128. http://dx.doi.org/10.1037/h0034225.

Keltner, D., \& Gross, J. J. (1999). Functional accounts of emotions. Cognition and Emotion, 13, 467-480. http://dx.doi.org/10.1080/026999399379140,

Keltner, D., \& Haidt, J. (1999). Social functions of emotions at multiple levels of analysis. Cognition and Emotion, 13, 505-522. http://dx.doi.org/10.1080/026999399379168.

Kiesler, D. J. (1983). The 1982 interpersonal circle: A taxonomy for complementarity in human interactions. Psychological Review, 90, 185-214. http://dx.doi.org/10.1037/ 0033-295X.90.3.185.

Knutson, B. (1996). Facial expressions of emotion influence interpersonal trait inferences. Journal of Nonverbal Behavior, 20, 165-182. http://dx.doi.org/10.1007/BF02281954.

Kurzban, R., \& Leary, M. R. (2001). Evolutionary origins of stigmatization: The functions of social exclusion. Psychological Bulletin, 127, 187-208. http://dx.doi.org/10.1037/ 0033-2909.127.2.187.

Leary, T. (1957). Interpersonal diagnosis of personality. New York: Ronald Press.

Leary, M. R., Cottrell, C. A., \& Phillips, M. (2001). Deconfounding the effects of dominance and social acceptance on self-esteem. Journal of Personality and Social Psychology, 81, 898-909. http://dx.doi.org/10.1037/0022-3514.81.5.898.

Leary, M. R., Twenge, J. M., \& Quinlivan, E. (2006). Interpersonal rejection as a determinant of anger and aggression. Personality and Social Psychological Review, 10, 111-132. http://dx.doi.org/10.1207/s15327957pspr1002_2.

Lelieveld, G., Van Dijk, E., Van Beest, I., \& Van Kleef, G. A. (2012). Why Anger and Disappointment Affect Other's Bargaining Behavior Differently: The Moderating Role of Power and the Mediating Role of Reciprocal and Complementary Emotions. Personality and Social Psychology Bulletin, 38(9), 1209-1221.

Lind, E. A., \& Tyler, T. R. (1988). The social psychology of procedural justice. New York: Plenum Press.

Mallott, M., Maner, J. K., DeWall, C. N., \& Schmidt, N. B. (2009). Compensatory deficits following rejection: The role of social anxiety in disrupting affiliative behavior. Depression and Anxiety, 26, 438-446. http://dx.doi.org/10.1002/da.20555.

Marsh, A. A., Ambady, N., \& Kleck, R. E. (2005). The effects of fear and anger facial expressions on approach- and avoidance-related behaviors. Emotion, 5, 119-124. http://dx.doi.org/10.1037/1528-3542.5.1.119.

Nezlek, J. B., Kowalski, R. M., Leary, M. R., Blevins, T., \& Holgate, S. (1997). Personality moderators of reactions to interpersonal rejection: Depression and trait self-esteem. Personality and Social Psychology Bulletin, 2, 1235-1244. http://dx.doi.org/10.1177/ 01461672972312001. 
Richman, L. S., \& Leary, M. R. (2009). Reactions to discrimination, stigmatization, ostracism, and other forms of interpersonal rejection: A multimotive model. Psychological Review, 116, 365-383. http://dx.doi.org/10.1037/a0015250.

Sacco, D. F., Wirth, J. H., Hugenberg, K., Chen, Z., \& Williams, K. D. (2011). The world in black and white: Ostracism enhances the categorical perception of social information. Journal of Experimental Social Psychology, 47, 836-842. http://dx.doi.org/10.1016/ j.jesp.2011.03.001.

Shaver, P., Schwartz, J., Kirson, D., \& O'Connor, C. (1987). Emotion knowledge: Further exploration of a prototype approach. Journal of Personality and Social Psychology, 52, 1061-1086. http://dx.doi.org/10.1037/0022-3514.52.6.1061.

Sinaceur, M., \& Tiedens, L. (2004). Get mad and get more than even: When and why anger expression is effective in negotiations. Journal of Experimental Social Psychology, 42, 314-322. http://dx.doi.org/10.1016/j.jesp.2005.05.002.

Tiedens, L. Z. (2001). Anger and advancement versus sadness and subjugation: The effect of negative emotion expressions on social status conferral. Journal of Personality and Social Psychology, 80, 86-94. http://dx.doi.org/10.1037/0022-3514.80.1.86.

Tiedens, L. Z., Ellsworth, P. C., \& Mesquita, B. (2000). Stereotypes about sentiments and status: Emotional expectations for high- and low-status group members. Personality and Social Psychology Bulletin, 26, 560-574. http://dx.doi.org/10.1177/0146167200267004.

Tooby, I., \& Cosmides, L. (1990). The past explains the present: Emotional adaptations and the structure of ancestral environments. Ethology and Sociobiology, 11, 375-424. http://dx.doi.org/10.1016/0162-3095(90)90017-Z.

Van Beest, I., Van Kleef, G. A., \& Van Dijk, E. (2008). Get angry, get out: The interpersonal effects of anger communication in multiparty negotiation. Journal of Experimental Social Psychology, 44, 993-1002. http://dx.doi.org/10.1016/i.jesp.2008.02.008.

Van Beest, I., \& Williams, K. D. (2006). When inclusion costs and ostrasicm pays, ostrasicm still hurts. Journal of Personality and Social Psychology, 91, 918-928. http://dx.doi.org/ 10.1037/0022-3514.91.5.918.

Van Beest, I., \& Williams, K. D. (2011). "Why hast thou forsaken me?" The effect of thinking about being ostracized by God on well-being and prosocial behavior. Social Psychological and Personality Science, 2, 379-386. http://dx.doi.org/10.1177/ 1948550610393312 .

Van Beest, I., Williams, K. D., \& van Dijk, E. (2011). Cyberbomb: Effects of being ostracized from a death game. Group Processes and Intergroup Relations, 1-16. http://dx.doi.org/ $10.1177 / 1368430210389084$.

Van Kleef, G. A. (2010). Don't worry, be angry? Effects of anger on feelings, thoughts, and actions in conflict and negotiation. In M. Potegal, G. Stemmler, \& C. D. Spielberger (Eds.), Handbook of anger (pp. 545-560). New York: Springer.

Van Kleef, G. A., De Dreu, C. K. W., \& Manstead, A. S. R. (2010). An interpersonal approach to emotion in social decision making: The emotions as social information model
Advances in Experimental Social Psychology, 42, 45-96. http://dx.doi.org/10.1016/ S0065-2601(10)42002-X

Vingerhoets, A. J. J. M., Cornelius, R. R., Van Heck, G. L., \& Becht, M. C. (2000). Adult crying: A model and review of the literature. Review of General Psychology, 4, 354-377. http://dx.doi.org/10.1037/1089-2680.4.4.354.

Wiggins, J. (1979). A psychological taxonomy of trait descriptive terms. The interpersona domain. Journal of Personality and Social Psychology, 37, 395-412. http://dx.doi.org/ 10.1037/0022-3514.37.3.395.

Wiggins, J. S., \& Broughton, R. (1985). The interpersonal circle: A structural model for the integration of personality research. In R. Hogan, \& W. H. Jones (Eds.), Perspectives in personality (pp. 1-47). Greenwich, CT: JAI Press, Inc.

Williams, K. (2001). Ostracism: The power of silence. New York: Guilford Press.

Williams, K. D. (2007). Ostracism. Annual Review of Psychology, 58, 425-452. http://dx.doi.org/10.1146/annurev.psych.58.110405.085641.

Williams, K. D. \& Jarvis, B. (2006). Cyberball: A program for use in research on ostracism and interpersonal acceptance. Behavior Research Methods, Instruments, E Computers, 38, 174-180. http://dx.doi.org/10.3758/BF03192765.

Wirth, J. H., \& Williams, K. D. (2009). “They don't like our kind”: Consequences of being ostracized while possessing a group membership. Group Processes and Intergroup Relations, 12, 111-127. http://dx.doi.org/10.1177/1368430208098780.

Wojciszke, B. (2005). Affective concomitants of information on morality and competence. European Psychologist, 10, 60-70. http://dx.doi.org/10.1027/10169040.10.1.60.

Wojciszke, B., Bazinska, R., \& Jaworski, M. (1998). On the dominance of moral categories in impression formation. Personality and Social Psychology Bulletin, 24, 1251-1263. http://dx.doi.org/10.1177/01461672982412001.

Wubben, M., De Cremer, D., \& Van Dijk, E. (2009). How emotion communication guides reciprocity: Establishing cooperation through disappointment and anger Journal of Experimental Social Psychology, 45, 987-990. http://dx.doi.org/10.1016 j.jesp.2009.04.010.

Zadro, L., Williams, K. D., \& Richardson, R. (2004). How low can you go? Ostracism by a computer is sufficient to lower self-reported levels of belonging, control, self-esteem, and meaningful existence. Journal of Experimental Social Psychology, 40, 560-567. http://dx.doi.org/10.1016/j.jesp.2003.11.006.

Zeelenberg, M., Nelissen, R. M. A., Breugelmans, S. M., \& Pieters, R. (2008). On emotion specificity in decision making: Why feeling is for doing. Judgment and Decision Making, 3, 18-27.

Zeifman, D. M. (2001). An ethological analysis of human infant crying: Answering Tinbergen's four questions. Developmental Psychobiology, 39, 265-285. http://dx.doi.org/ 10.1002/dev.1005. 